\title{
Intercultural Competence in Learning English as a Foreign Language in Indonesia: a Pragmatic Analysis
}

\author{
Fardini Sabilah \\ University of Muhammadiyah Malang \\ fsabilah@yahoo.com
}

\begin{abstract}
This paper reports the findings of my doctoral research on intercultural competence in learning English as a foreign language in elementary schools. The data were collected from the field research based on observation and interviews with teachers and students and were analyzed using descriptive quantitative and qualitative approaches. This research aimed at identifying speech acts of intercultural competence in learning English. It explores the contextual approaches to teaching and learning English with particular contents to cultures. The main research question is: How are the expressions of speech accused in the intercultural competence study conceptualized in learning English in elementary schools in Indonesia? Consequently, the intercultural competence requires the learners to develop relevant knowledge and skills regarding target language and culture as well as their cultural awareness. Intercultural competence in English for elementary schools is of urgency to acquire so as to equip students with interactional competence in using foreign language. Meanwhile, intercultural pragmatics as the theory of analysis constitutes the investigation on the process of acquiring the comprehension on speech acts and how the knowledge on speech acts in second language acquisition is achieved. This research has implications for English teachers, textbook writers, as well as the curriculum and pedagogy in Indonesia.
\end{abstract}

Keywords: culture, intercultural competence, intercultural pragmatics

\section{INTRODUCTION}

Intercultural competence in elementary school is as a key focus in foreign language education. It aims to achieve students' independence in communicating values and personal point of view. It means students need to develop their knowledge and skills to compare the view of the world from their own languages and cultures with that of the languages and cultures they have learned and be able to apply the knowledge and skills they have learned to their own cultures and societies. Specifically, the skills that they will need to develop are 'a critical understanding of a culture and practices other than one's own', and 'an appreciation of the uniqueness of the other culture(s)'.
The design of intercultural competence-based English instructional activities for elementary school that has been viewed from pragmatic studies will be able to implant holistic cultural awareness into students' conception, particularly those manifested in lingual forms. In this present research, the concern is more on grammatical point. Grammatical forms comprise the aspects of grammar such as: phoneme, morpheme, word, phrase, clause, sentence types, speech act, as well as discourse. All of which display cultural differences (in using the languages) between students' first and target languages. Grammatical units in this current research refer to forms of utterance which are used to express an illocution's attempts in any language [1]. The investigated grammatical units were in the forms of morphemes (markers), words (word marking), phrases, clauses, sentence structures, or other unit markers. In addition, another grammatical unit investigated in this current study is speech act as those in [2] and [3], the functions of speech act [4], as well as speech act theories put forward [5].

This paper reported the use of speech act of intercultural competence in English instruction at elementary school. Specifically, the English instruction focuses on elementary school student's grade IV, V, and VI. The upper graders are chosen because they have had enough English vocabulary building and been assumed to be ready to be exposed to lingual and non-lingual concepts of the target language.

The term intercultural competence, as used in this research, refers to the elements of intercultural communication - that is, where knowledge of another language and culture enables a learner to interact effectively with people from that culture, and negotiate between that culture and his/her own [6]. As suggested above, a precise contextual definition may be said to be still under construction. The researcher similarly suggests that better definition of this term will be for teachers an important element in more effectively describing and recognizing the desired outcomes of intercultural language learning.

The theoretical basis of this current research is intercultural pragmatics that puts it main concern on the acquirement and use of pragmatic norms in second language acquisition, how learners of second language produce and comprehend speech acts, and how their pragmatic competence develops along the time [7]. [8] Assert that intercultural pragmatics constitutes the 
investigation on the process of acquiring the comprehension on speech acts and how the knowledge on speech acts in second language acquisition is achieved. Besides, intercultural pragmatics investigates the speech act behaviors of foreign language learners, both children and adults. The aspects of speech acts socio-pragmatically investigated in this current research fall within the framework of intercultural pragmatic theories.

The aim of this research is to identify the speech acts of intercultural competence in learning English. It explores the contextual approaches to teaching and learning English with particular contents to cultures. The research question is: How are the expressions of speech acts used in the intercultural competence study conceptualized in learning English in elementary schools in Indonesia? This research started with preliminary research to obtain the general information about the teaching of English in elementary schools in Malang to investigate teachers' perspectives towards culture and intercultural competence.

\section{METHOD}

The current research was conducted by means of descriptive and interpretive study designs, further analyzed by qualitative and quantitative methods. The data were collected by means of observation, in-depth interview, questionnaires, Focus Group Discussion (FGD) involving experts by integrating the techniques of listening, recording, taking notes, and making checklist. In the field implementation, audio visual recording was used to gather accurate data. There were quantitative and qualitative data to be collected. The observation was done in class during the teaching-learning process. The interview was conducted with the teachers, key informants, and students. Both observation and interview aimed at revealing speech acts types manifesting intercultural competence-based instructional materials. The questionnaire was designed to be closed-ended to tap the information related to the effectiveness of the design. FGD was conducted to verify the data collected from the observation, interview, and questionnaire. In specific, FGD generated more feedbacks for beter design of intercultural competence-based English instructional activities. The data were displayed informally, in which the data were presented descriptively and narratively, comprising meanings and functions of speech act found in the English instructional activities and summarized in the form of instructional design.

\section{RESULTS AND DISCUSSION}

This current research has resulted speech acts (further contract ed into SA) in the context of English instructional activities for elementary school. [2] explained that there are three types of SA in regards to meaning, namely (1) locutionary acts, (2) illocutionary acts, and (3) perlocutionary acts.
First, the theoretical findings show that based on the meaning of SA, most of SAs used by teachers and students in the classroom's instruction are locutionary acts $(62.5 \%)$. Meanwhile, only a small portion of illocutionary acts $(21.87 \%)$ and perlocutionary acts $(15.6 \%)$ was found in the intercultural competence-based English instruction. These findings indicated that the forms of SA between teachers and students in learning English as found in upper grades (IV, V, and VI) of elementary school conveyed information, knowledge, and new concept to the students.

As revealed [2], locutionary act is a meaning that arises from the real meaning of lexicon and its meaning can be the same or different from its illocutionary meaning. This is strongly influenced by the speaker's intention and purpose in speaking. The classroom instruction tends to use locutionary acts because those SAs are more easily understood by elementary school students who still need more oral explanations from the teacher. Those locutionary acts are found in the form of asking, introducing vocabulary, and sentence/grammatical concept. Meanwhile, SA which is not frequently found is perlocutionary acts. The pointed out that perlocutionary act is oriented to speakers in the form of impacts resulting from an utterance and this type of SA is less suitable to use in elementary school level because the language for this age should be simple and contextual [9], and thus locutionary act is more appropriate.

Within further investigation, this research has found three types of SA in regards to functions, namely assertive, expressive, and directive. Commissive and declarative SAs are not found. In intercultural competence-based English instruction, there are 11 assertive SAs found (33.3\%) from the teacher and students. As stated by [2] and [4], assertive SA is a form of SA that binds the speaker to the truth of the proposition being expressed in the speech. Out of five assertive forms, only 'stating' type is found; whereas suggesting, boasting, complaining, and claiming are not. It implies that the function of expression in intercultural competence-based English instruction is SA which serves to convey a truth of a concept. Departing from the result, the SA used by the teacher to the students in the context of English classroom instruction serves to convey information and explain a new knowledge.

Referring back to the data, there is only one directive SA found (33.3\%), namely 'command' SA; whereas order, plead, advice, and recommend SA are not found. The reason is because the use of this sort of SA is in line with the aim of teaching and learning process. The teaching of English in elementary school is oriented to the modeling form, and thus it is not surprising that the most common SA found is 'command' form. The meaning of 'command' SA in this case is to ask the students to perform an action in accordance with the teacher's utterance. This finding underpins [10] research revealing that foreign language learning at elementary school is likely more successful provided that the teacher acts as a model and fully facilitates students' learning. 
As of expressive SA, there is also only one function found $(33.3 \%)$, praising; while the function of thanking, congratulating, apologizing, blaming, and condolence are not found. This sort of SA, praising, is very effective to implement in giving instructions to the young learners. [11]proposes that the characteristics of young learners are curios, short concentration range, limited cognitive development, boredom, mimicry, keen on new and real things, fond of motor physical activity, keen on group activities, enthusiastic about telling about themselves, aggressive, happy to be praised, fond of competing, and others. To that end, the finding of this research supports [11] theory.

The following section further exemplifies how those SAs are expressed in the intercultural competence study conceptualized in learning English in elementary schools in Indonesia. The first part is to exemplify the commonly used SA in regards to meaning that is locutionary act. Refer to the following sample utterances.

[1] Christians go to church on every Sunday. Moslems pray Jum 'at on every Friday.

Source: Data DLN 4.5

[2] I have a breakfast at 6 a.m.

I have a lunch at 1 p.m.

I have a dinner at 7 p.m.

Source: Data DLE 5.1

Projected as conveying locutionary acts, the above sample utterances have arisen from their real meaning of each lexicon constructed by each sentence constituent. There is no difference between the used lexicon and the speaker's intention in speaking, introducing the intercultural concepts of different religion worshipping rituals and eating habits, shown in example [1] and [2] respectively. This sort of SA is frequently found in English instruction for elementary school as it is deemed easily comprehensible.

As for how SAs are expressing different functions, three types of function have been apparent - assertive, directive, and expressive. The followings serve as the sample utterances.

[3] Teacher: 'A pronoun for mother is she, father is he,

What about mother and I?'

Students: 'we'

Source: Data DLPr 6.1

[4] Teacher: What are the seasons in Indonesia?

Students: Dry and rainy

Teacher: Good. What about in Western countries? Mention the seasons.

Students: Summer, spring, winter, and autumn.

Source: Data DLN 4.4

Example [3] conveys assertive function - stating. It is shown by the statement of a teacher to amplify the students' comprehension on the use of different pronouns in English that do not specifically exist in Bahasa Indonesia, and thus intercultural awareness to raise. Behaving similarly to express different functions of SA, the sample conversation [4] illustrates expressive and directive functions. The expressive function of SA is represented by the use of praising word "good" to appreciate the students' ability to mention the seasons in Indonesia. The command word 'mention' is frequently used by the teacher to trigger the students to answer further about the seasons in Western countries that the students are not experiencing in their home country. These three functions of SA - stating, praising, and command - have been incorporated by the teacher upon teaching intercultural competence-based English materials for elementary school grade IV, V, and VI. All of which have supported the theories of foreign language learning pioneered [9] [11].

\section{CONCLUSION}

Based on the findings and discussion, it can be concluded that there is one speech act component which is locutionary act and three functions of speech act that have been mostly introduced in intercultural competencebased English instructional activities. The found speech acts are assertive, expressive, and directive. Locutionary act is a way more effective to implement than those of other SAs in intercultural competence-based English learning for elementary school grade IV, V, and VI. In the aspect of SA functions, the learning of intercultural competence in English lesson of elementary school has been dominated by the use of assertive (stating), directive (praising), and expressive (command) SAs. To end with, the use of SAs is to facilitate the students to be active in communicating intercultural-related topics in the target language.

\section{REFERENCES}

[1] Leech, G. Principles of Pragmatics. London: Longman Inc. (1983).

[2] Searle, J. R. Speech Acts: An Essay in the Philosophy of Language. London: Cambridge University Press. (1983).

[3] Wijana, I. P., et al. Sosiolinguistik: Kajian Teori dan Analisis. (Sociolinguistics: Theory and Analysis Study). Yogyakarta: PustakaPelajar. (2006).

[4] Tarigan, H. Pengajaran Pragmatik (Pragmatics Study). Bandung: Angkasa Bandung.(2009).

[5] Rahardi, K. Sosiopragmatik. (Sociopragmatics). Jakarta: Penerbit Erlangga.(2009).

[6] Guilherme, M. Critical Citizens for an Intercultural World: Foreign Language Education as Cultural Politics. Sydney: Multilingual Matters Ltd.(2004).

[7] Kecskes, I. Intercultural Pragmatics. Oxford University Press.(2014).

[8] Kasper, G. and Dahl, M. "Research Methods in Interlanguage Pragmatics." Studies of Second Language Acquisition 13.2: 215-247.(1991).

[9] Paul, D. Teaching English to Children in Asia. Hong Kong: Longman Asia ELT.(2003).

[10] Moloney, R. A. Intercultural Competence in Young Language Learners: A Case Study (Dissertation) Sydney: University of Sydney.(2007). 
[11] Brumfit, Ch. Teaching English to Children. London: An International Publishing Company

[12] Borg, W. R, Gal. M.D. (1983). Educational Research: An Introduction. New York \& London: Longman.(1994).

[13] Jin, T. Intercultural Competence in the Learning of Chinese as a Foreign Language in the UK - An Exploratory Study.(http://www.ioe.ac.uk) Retrieved on March 28, 2014.(2012).

[14] Levinson, S. C. Pragmatics. London: Cambridge University Press.(1983). 